\title{
Changes in root canal anatomy using three nickel-titanium rotary system - A cone beam computed tomography analysis
}

\author{
Carlos Menezes Aguiar', Fernanda Araujo Donida', Andréa Cruz Câmara', Marco Frazão² \\ 1'Department of Prosthetics and Oral and Facial Surgery, Faculty of Dentistry, Federal University of Pernambuco, Recife, PE, Brazil \\ ${ }^{2}$ Private Practice, Recife, PE, Brazil
}

\begin{abstract}
Aim: Cone beam computed tomography (CBCT) was used to evaluate the ability of three NiTi rotary systems to maintain the original root canal anatomy. Methods: Sixty mesiobuccal canals of human mandibular first molars were divided into three groups with 20 root canals each. All teeth were scanned by CBCT before instrumentation. The images were captured digitally for further analysis using the Image Tools Software. The images were sectioned in three points, located at 9 $\mathrm{mm}, 6 \mathrm{~mm}$ and $3 \mathrm{~mm}$ from the apex. In Group 1, the root canals were instrumented with ProTaper Universal ${ }^{\mathrm{TM}}$ rotary system; in Group 2, with Twisted File ${ }^{\mathrm{TM}}$ rotary system; and in Group 3, with $M_{\text {two }}{ }^{T M}$ rotary system. Instrumented teeth were scanned again using CBCT and the images of the uninstrumented canals were compared with images of the instrumented canals. The results were statistically analyzed using the one-way ANOVA test. A level of significance of 0.05 was adopted. Results: The means of $D 1$ at distances of $9 \mathrm{~mm}, 6 \mathrm{~mm}$, and $3 \mathrm{~mm}$ from the apex were, respectively: Group 1: $0.88 \pm 0.257,1.00 \pm 0.000$, and 1.00 \pm 0.000 ; Group 2: $0.79 \pm 0.745,0.65 \pm 0.669$, and $0.25 \pm 0$; Group 3: $0.50 \pm 0.745,0.33 \pm 0.472$, and $0.03 \pm 0.104$. The means of D2 at distances of 9 $\mathrm{mm}, 6 \mathrm{~mm}$, and $3 \mathrm{~mm}$ from the apex were respectively: Group 1: $1.00 \pm 0.00,1.00 \pm 0.00$, and $1.00 \pm 0.00$; Group 2: $0.41 \pm 0.299,0.30 \pm 0.428$, and $0.50 \pm 0.707$; Group 3: $0.58 \pm 0.910$, $0.85 \pm 1.857$, and $0.31 \pm 0.643$. Conclusions: The CBCT analysis revealed that the ProTaper Universal ${ }^{\mathrm{TM}}$ produced centered preparations and while the Twisted File ${ }^{\mathrm{TM}}$ and $\mathrm{M}_{\mathrm{two}}{ }^{\mathrm{TM}}$ rotary systems produced canal deviation.
\end{abstract}

Keywords: root canal preparation, tomography, emission-computed.

\section{Introduction}

Root canal preparation is an important part of endodontic treatment. One of the main objectives in root canal preparation is to develop a shape that tapers from apical to coronal, maintaining the original canal shape ${ }^{1}$. Instruments should

Received for publication: August 26, 2013 Accepted: November 25, 2013

Correspondence to: Carlos Menezes Aguiar Rua Aristides Muniz, 70/501, CEP: 51020-150 Boa Viagem, Recife, PE, Brasil Phone: +55 8134676821 E-mail: cmaguiar.ufpe@yahoo.com.br remain centered in the root canal throughout the preparation ${ }^{2}$. Nickel-titanium (NiTi) rotary instruments, due to their superelastic behavior, are able to maintain the original canal shape without significant deviation or create irregularities such as zipping, ledges, perforations or danger zones in curved canals. Many types of rotary root canal instruments have been introduced, varying in cross-section, blade, pitch design and taper ${ }^{3}$.

The ProTaper ${ }^{\mathrm{TM}}$ NiTi rotary system has been upgraded to the ProTaper Universal ${ }^{\mathrm{TM}}$ rotary system, which includes shaping, finishing and retreating instruments. It 
incorporates a shallow, U-shaped groove at each of its convex triangular sides in cross-section, supposedly to improve flexibility in the larger instruments. The modified design has also been suggested to reduce the subjective feeling of the instrument being "pulled" into the canal or so-called screw-in effect ${ }^{4-6}$.

A completely different manufacturing process has been developed by SybronEndo to create a new rotary file for root canal preparation called the Twisted File ${ }^{\mathrm{TM}}$ (SybronEndo, Orange, CA, USA). These files have a triangular cross section with constant tapers of $.04, .06, .08, .10$, and .12 . They are available in five tip sizes from 25 to 50 . The manufacturer claims that the three new manufacturing processes of these files, namely R-phase heat treatment, twisting of the metal, and special surface conditioning, significantly increase the instrument's resistance to cyclic fatigue and flexibility, even with .06-, .08-, .10-, and .12-tapered instruments, maintaining the original canal center and minimizing canal transportation even in severely curved root canals $s^{1,7,8}$.

$\mathrm{M}_{\text {two }}{ }^{\mathrm{TM}}$ (VDW; Antaeus, Munich, Germany) is a newly developed NiTi rotary system. $\mathrm{M}_{\text {two }}$ instruments have an Sshaped cross-sectional design, a positive rake angle with 2 cutting edges, no radial lands, progressive blade camber (pitch) in the apical-coronal direction and a noncutting tip ${ }^{9-11}$.

In order to investigate the efficiency of instruments and techniques developed for root canal preparation, a number of methods have been used to compare canal shape before and after preparation. Cone beam computed tomography ( $\mathrm{CBCT}$ ) imaging techniques have been evaluated as noninvasive methods for the analysis of canal geometry and efficiency of shaping techniques. Using this technique it is possible to compare the anatomic structure of root canal before and after instrumentation ${ }^{1,12}$.

The present study was set out to determine the changes in root canal anatomy using the ProTaper Universal ${ }^{\mathrm{TM}}$, Twisted File ${ }^{\mathrm{TM}}$ and $\mathrm{M}_{\text {two }}{ }^{\mathrm{TM}}$ rotary systems analyzed by CBCT.

\section{Material and methods}

\section{Selection and preparation of samples}

Sixty mesiobuccal canals of extracted human mandibular first molars (length $20-21 \mathrm{~mm}$ ) obtained from the tooth bank of the Department of Prosthetics and Oral and Facial Surgery of the Federal University of Pernambuco, Brazil were selected with the approval of the Ethics in Research Committee of the Center of Health Sciences of the University. The mesiobuccal roots had completely formed apices and curved root canals whose curvature ranged from $25^{\circ}$ to $30^{\circ}$ according to the canal access angle (CAA) technique ${ }^{13}$. The access cavities were prepared, and to determine the working length (WL) a \#10 SenseusFlexofile (Dentsply/Maillefer, Ballaigues, Switzerland) was inserted into the mesiobuccal canal until it was visible at the apical foramen. The WL was calculated to be $1 \mathrm{~mm}$ less than the length obtained with this initial file.

\section{Preoperative images}

The roots were stored in alginate hydrogel (Jeltrade; Dentsply, Petrópolis, RJ, Brazil) poured in plastic containers to ensure a very close approximation of the preoperative and postoperative images according to a previously described method $^{14}$.

After the alginate solidified, all teeth were scanned by CBCT (i-Cat ${ }^{\mathbb{}}$; Imaging Sciences International, Hatfield, PA, USA) to determine the root canal shape before instrumentation. The exposure time was $26.9 \mathrm{~s}$, operating at $120 \mathrm{kV}$ and $7 \mathrm{~mA}$. The images were sectioned in three points, located respectively at $9 \mathrm{~mm}$ (coronal level), $6 \mathrm{~mm}$ (middle level) and $3 \mathrm{~mm}$ (apical level) from the apex. The images were stored in a computer for later comparison.

\section{Root canal preparation}

The specimens were randomly divided into three groups with 20 root canals each. All instrumentation was performed according to each manufacturer's instructions. Random distribution of the groups considered the degree of canal curvature, allowing the average curvature, as well as the more severe cases, to be evenly allocated to each group:

Group 1: ProTaper Universal ${ }^{\mathrm{TM}}$ Rotary System. The canals were instrumented at a rotational speed of $300 \mathrm{rpm}$ as follows: (a) the SX file was used up to one half of the WL, (b) the S1 file was used up to $4 \mathrm{~mm}$ short of the apex, (c) the $\mathrm{S} 1$ and S2 files were used to the full WL, and (d) the F1 and F2 files were used to the full WL.

Group 2: Twisted File ${ }^{\mathrm{TM}}$ Rotary System. The canals were instrumented at a rotational speed of $300 \mathrm{rpm}$ as follows: (a) the \#25.08 file was used up to the coronal third of the root canal, (b) the \#25.06 file was used up to $4 \mathrm{~mm}$ short of the WL, and (c) the \#25.04 and \#25.06 files were used up to the full WL.

Group 3: $\mathrm{M}_{\text {two }}{ }^{\mathrm{TM}}$ Rotary System. The canals were instrumented at a rotational speed of $300 \mathrm{rpm}$ as follows: the \#10.04, \#15.05, \#20.06, and \#25.06 files were used up to the full WL.

The specimens were fastened to a morse (Neboluz, São Paulo, SP, Brazil) to keep them fixed during preparation. After use of each file, the root canals were irrigated with 3 $\mathrm{mL}$ of a freshly prepared $1 \%$ sodium hypochlorite solution (Roval, Recife, PE, Brazil). Glyde ${ }^{\mathrm{TM}}$ (Dentsply Maillefer) was used as a lubricant during instrumentation. A single operator experienced in rotary systems prepared all root canals. Each instrument was changed after five canals. Instruments were examined after every use to record and reject deformed or fractured instruments. An electric motor (Driller Endo-Pro Torque, São Paulo, SP, Brazil) was used.

\section{Postoperative images}

After instrumentation, the specimens were scanned under the same conditions as the initial scans and the postoperative images were captured in the same way as mentioned before.

\section{Evaluation of centering ability}

Using the Image Tool software (University of Texas Health Science Center, San Antonio, TX, USA) the 


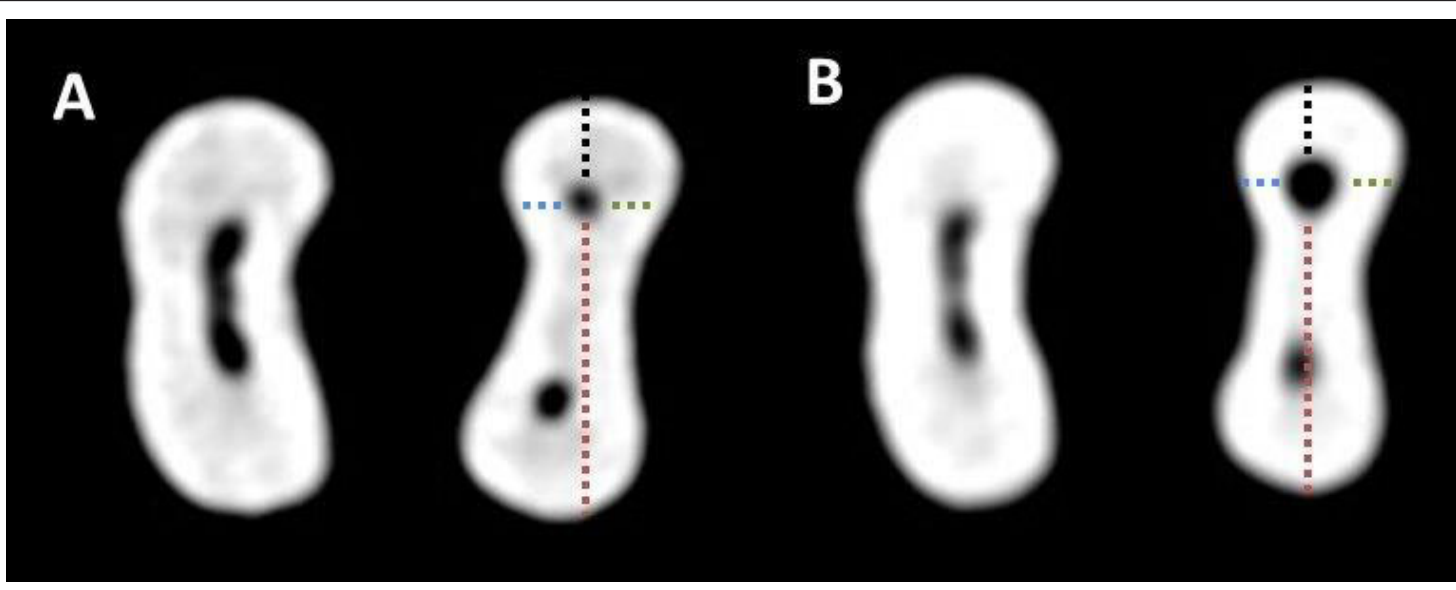

Fig. 1. $C B C T$ scan images showing the centering ability of the ProTaper Universal ${ }^{\mathrm{TM}}$ before $(\mathrm{A})$ and after $(\mathrm{B})$ preparation at apical level.

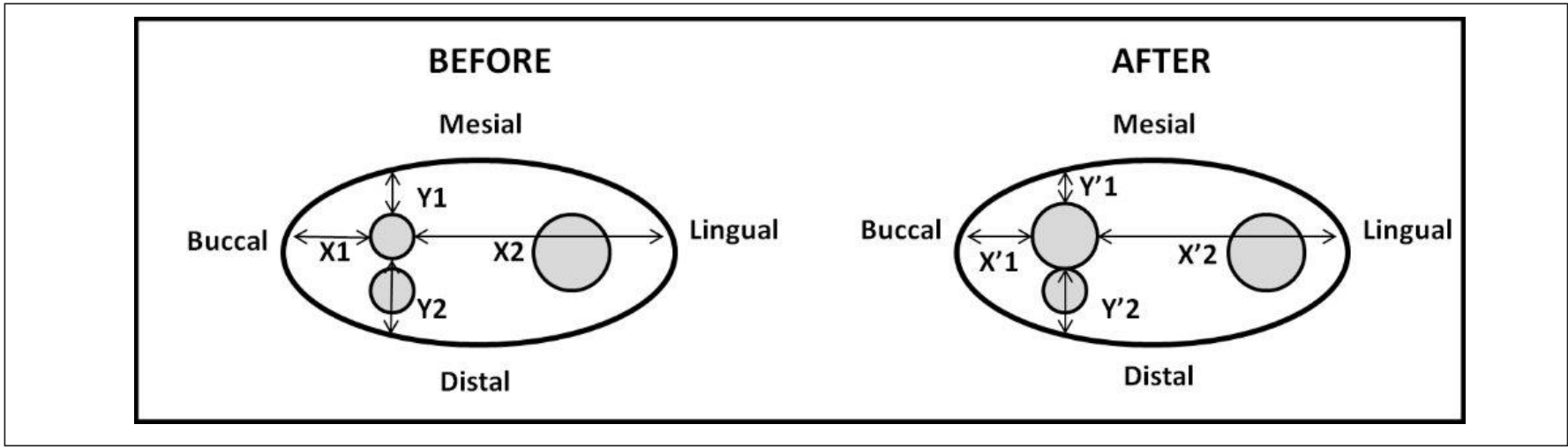

Fig. 2. Schematic presentation of the image used in the evaluation.

preoperative and postoperative images were compared (Figure 1, A and B). Gambill et al. ${ }^{15}$ (1996) defined centering ratio as the measurement of the ability of the instrument to stay centered in the canal. This ratio was calculated for each section using the following ratio (Figure 2):

D1: $\left(\mathrm{X} 1-\mathrm{X}^{\prime} 1\right) /\left(\mathrm{X} 2-\mathrm{X}^{\prime} 2\right)$

D2: (Y1 - Y'1)/(Y2 - Y'2)

Where $\mathrm{D} 1=$ the buccolingual measurement and $\mathrm{D} 2=$ the mesiodistal measurement. $\mathrm{X} 1=$ shortest distance from the buccal aspect of the root to the periphery of the uninstrumented canal. $X^{\prime} 1=$ shortest distance from the buccal aspect of the root to the periphery of the prepared canal. $\mathrm{X} 2=$ shortest distance from the lingual aspect of the root to the periphery of the uninstrumented canal. $X^{\prime} 2=$ shortest distance from the lingual aspect of the root to the periphery of the prepared canal. Y1 = shortest distance from the mesial aspect of the root to the periphery of the uninstrumented canal. Y'1 = shortest distance from the mesial aspect of the root to the periphery of the prepared canal. $Y 2=$ shortest distance from the distal aspect of the root to the periphery of the uninstrumented canal. Y'2 $=$ shortest distance from the distal aspect of the root to the periphery of the prepared canal. According to this formula, a result of 1 indicates a perfect centering ability; the closer the result is to zero, the worse is the ability of the instrument to remain centered.

\section{Statistical analysis of the data}

The categorical data were summarized by means of absolute frequency and relative percentage, and the numerical data by means of the usual descriptive statistics of location and dispersion. The results were statistically analyzed using one-way ANOVA test. A level of significance of 0.05 was adopted, using the Statistical Package for the Social Sciences, version 13 (SPSS, Chicago, IL, USA).

\section{Results}

Table 1 and Figure 3 present the main descriptive statistics of the buccolingual measurement (D1) and mesiodistal measurement (D2) according to the rotary system used and the instrumented root segment at distances of $9 \mathrm{~mm}$ (coronal), 6 $\mathrm{mm}$ (middle) and $3 \mathrm{~mm}$ (apical) from the apex.

The means of D1 ranged from 0.03 to 1.00 . In group 1 , the mean deviation was $0.88 \pm 0.257,1.00 \pm 0.000$, and $1.00 \pm 0.000$ at distances of $9 \mathrm{~mm}$ (coronal), $6 \mathrm{~mm}$ (middle) and $3 \mathrm{~mm}$ (apical) from the apex, respectively. In group 2, the mean deviation was $0.79 \pm 0.745,0.65 \pm 0.669$, and $0.25 \pm 0.425$ at distances of $9 \mathrm{~mm}$ (coronal), $6 \mathrm{~mm}$ (middle) and $3 \mathrm{~mm}$ (apical) from the apex, respectively. In group 3, the mean deviation was $0.50 \pm 0.745,0.33 \pm 0.472$, and $0.03 \pm 0.104$ at distances of $9 \mathrm{~mm}$ (coronal), $6 \mathrm{~mm}$ (middle) 


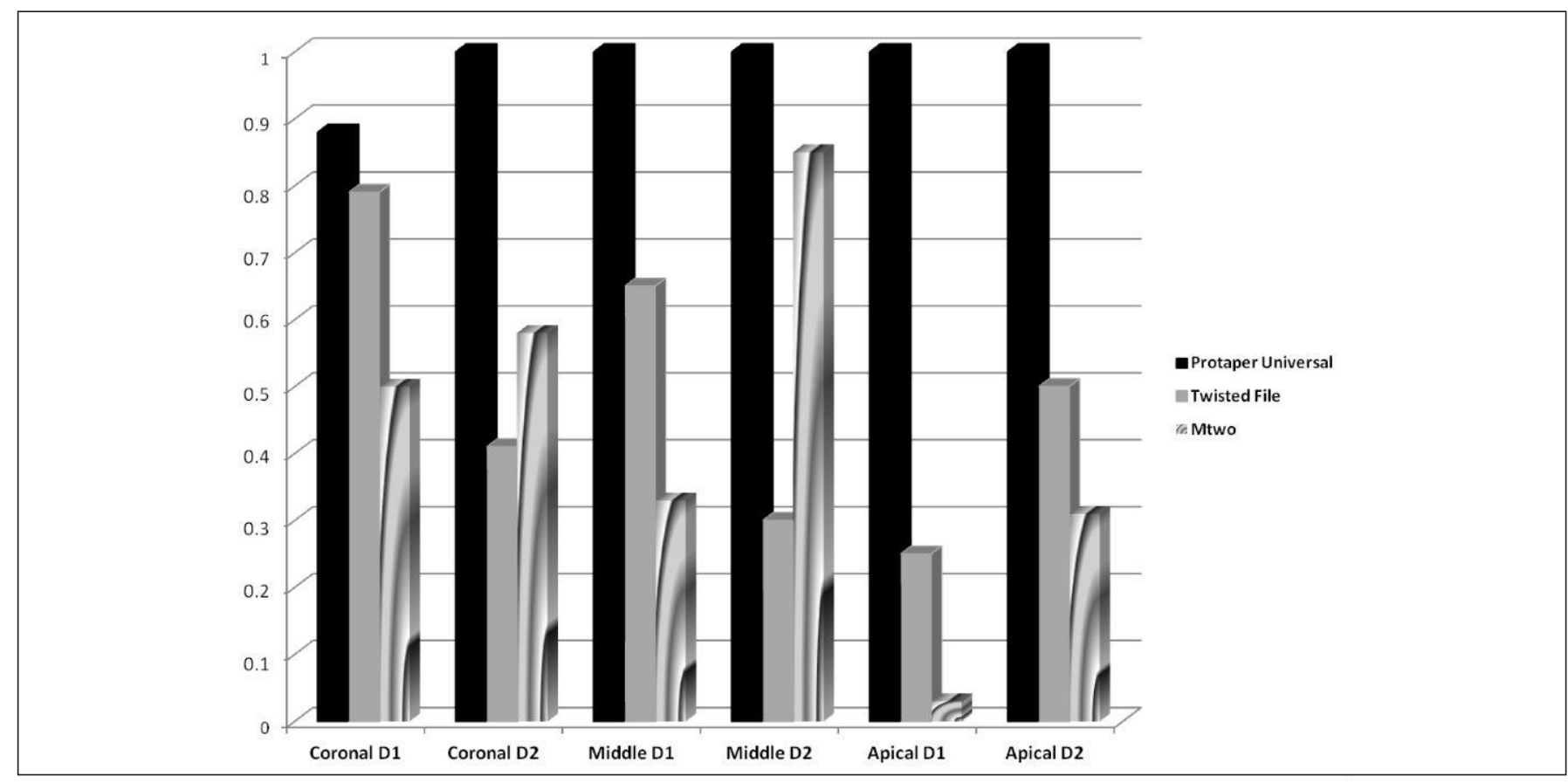

Fig. 3. Mean of the D1 (buccolingual) and D2 (mesiodistal) measurements according to the used instrument and the instrumented root segment.

Table 1. Mean and standard deviation of the buccolingual and mesiodistal measurements according to the instrument used and the root segment instrumented.

\begin{tabular}{lllll}
\hline \multirow{2}{*}{ Third } & \multicolumn{3}{c}{ Instrument } & \\
\cline { 2 - 4 } & $\begin{array}{c}\text { PTU } \\
\text { Mean } \pm \text { SD }\end{array}$ & $\begin{array}{c}\text { TF } \\
\text { Mean } \pm S D\end{array}$ & $\begin{array}{c}\mathbf{M}_{\text {two }} \\
\text { Mean } \pm S D\end{array}$ & $p$ value \\
\hline Coronal D1 & $0.88 \pm 0.257$ & $0.79 \pm 0.745$ & $0.50 \pm 0.745$ & 0.171 \\
Coronal D2 & $1.00 \pm 0.000$ & $0.41 \pm 0.299$ & $0.58 \pm 0.910$ & 0.001 \\
Middle D1 & $1.00 \pm 0.000$ & $0.65 \pm 0.669$ & $0.33 \pm 0.472$ & 0.012 \\
Middle D2 & $1.00 \pm 0.000$ & $0.30 \pm 0.428$ & $0.85 \pm 1.857$ & 0.003 \\
Apical D1 & $1.00 \pm 0.000$ & $0.25 \pm 0.425$ & $0.03 \pm 0.104$ & $<0.001$ \\
Apical D2 & $1.00 \pm 0.000$ & $0.50 \pm 0.707$ & 0.310 .643 & 0.005
\end{tabular}

PTU: ProTaper Universal; TF: Twisted File; SD: standard deviation; D1: buccolingual measurement; D2: mesiodistal measurement

and $3 \mathrm{~mm}$ (apical) from the apex, respectively.

The means of D2 ranged from 0.30 to 1.00 . In group 1, the mean deviation was $1.00 \pm 0.00,1.00 \pm 0.00$, and $1.00 \pm 0.00$ at distances of $9 \mathrm{~mm}$ (coronal), $6 \mathrm{~mm}$ (middle), and $3 \mathrm{~mm}$ (apical) from the apex, respectively. In group 2, the mean deviation was $0.41 \pm 0.299,0.30 \pm 0.428$, and $0.50 \pm 0.707$ at distances of $9 \mathrm{~mm}$ (coronal), $6 \mathrm{~mm}$ (middle) and $3 \mathrm{~mm}$ (apical) from the apex, respectively. In group 3 , the mean deviation was $0.58 \pm 0.910,0.85 \pm 1.857$, and $0.31 \pm 0.643$ at distances of $9 \mathrm{~mm}$ (coronal), $6 \mathrm{~mm}$ (middle) and $3 \mathrm{~mm}$ (apical) from the apex, respectively.

There were statistically significant differences $(p<0.05)$ among the three groups, except for coronal D1.

\section{Discussion}

The introduction of NiTi alloy allowed the manufacture of instruments that were able to prepare curved root canals with safety, less deviations and in less working time, in comparison with stainless steel instruments ${ }^{3}$. New NiTi rotary systems are continuously being marketed, each having subtly different design features, which are claimed to improve flexibility, cutting efficiency, safety and ultimately canal shaping ${ }^{16,17}$. The present study evaluated the ability of three NiTi rotary systems to maintain the original root canal anatomy by using the CBCT. Several methodologies have been used to evaluate the final shape of root canal preparations such as the Serial Sectioning Technique and optical microscopy. However, when using these methods, part of the specimen structure is lost, because there is need to cut the tooth before the postoperative evaluation. The use of simulated root canals in resin blocks, in spite of allowing for a high degree of reproducibility and standardization, does not reflect the clinical behavior of the instruments, because of the different hardness of resin and dentine. Radiographic evaluation ${ }^{18}$, however, is not destructive, but allows only a two-dimensional evaluation of the root canal. CBCT has been adapted for dentistry and 
compared with medical tomography that leads to increased precision and resolution, as well as reducing the image acquisition time and, as ain consequence, the exposure time to radiation. Another advantage of this method is that there is no destruction of the sample ${ }^{19}$.

As reported by Flores et al..$^{20}$ (2012), CBCT and specialized software (i-CAT Cone Beam) were successfully used in the present research for measurements before and after instrumentation of root canals and for the calculations of the centering ability of three NiTi rotary systems during cleaning and shaping of the root canals. The present study evaluated the effects of ProTaper Universal ${ }^{\mathrm{TM}}, \mathrm{M}_{\mathrm{two}}{ }^{\mathrm{TM}}$, and TwistedFile ${ }^{\mathrm{TM}}$ on root canal anatomy. CBCT analysis showed that the ProTaper Universal ${ }^{\mathrm{TM}}$ showed the ability for producing centered preparations and the Twisted File ${ }^{\mathrm{TM}}$ and $\mathrm{M}_{\text {two }}{ }^{\text {тM }}$ Rotary Systems produced canal deviation. The use of this methodology was based on the study of Sanfelice et al. ${ }^{14}$ (2010) which showed it to be reliable, without destructive sectioning of the specimens or loss of the root material during sectioning. Previous studies showed that CBCT used to evaluate root canals prepared with NiTi rotary instruments provided a nondestructive and reproducible method ${ }^{12,14,21,22}$. Data obtained with this technique enable the identification of morphologic changes associated with different biomechanical preparations including canal deviation, dentin removal and final canal preparation. A major advantage of CBCT is the possibility to obtain highly accurate evaluation of root canal shape by the superimposition and measurement of $3 \mathrm{D}$ renderings ${ }^{23}$.

In the present research, in the group where the $\mathrm{M}_{\text {two }}{ }^{\text {тM }}$ rotary system was used, a larger number of deviations was observed. Hin et al. ${ }^{11}$ (2013) observed that instrumentation with $\mathrm{M}_{\text {two }}$ could cause damage to root canal dentin. These results are in disagreement with previous studies ${ }^{24,25}$. Schäfer et al. ${ }^{26}$ (2006) also demonstrated the efficiency of cleaning and shaping of this new instrument. Yang et al. ${ }^{9}$ (2011) showed that the $\mathrm{M}_{\text {two }}{ }^{\mathrm{T}}$ rotary system maintained the original curvature of the root canal as well as provided a good centering ability. The differences found in this research compared with previous studies $^{9,24,25,26}$ may be due to the fact that in this study mesiobuccal roots and curved root canals were used.

The current study showed that the Twisted File ${ }^{\mathrm{TM}}$ rotary systems produced morphological changes, such as apical deviation. These results are in disagreement with a previous study $^{27}$, which stated that the Twisted File ${ }^{\mathrm{TM}}$ rotary system can be used in any clinical case, regardless of the anatomical aspect of the tooth. According to Duran-Sindreu et al. ${ }^{28}$ (2012), the Twisted File ${ }^{\mathrm{TM}}$ instruments were designed to have improved properties in relation to root canal preparation as compared with other instruments. Stern et $\mathrm{al}^{16}$ (2012) reported that the Twisted File ${ }^{\mathrm{TM}}$ was able of producing centered preparations. Other authors ${ }^{1,29,30}$ also demonstrated the ability of the Twisted File $^{\mathrm{TM}}$ rotary system to maintain the original root anatomy in curved canals.

The results of the present research showed that the ProTaper Universal ${ }^{\mathrm{TM}}$ rotary system produced centered preparations maintaining the original root canal anatomy even in extremely curved canals, as demonstrated in previous studies $^{31-34}$. These results may be related to the modified cross section design of the ProTaper Universal ${ }^{\mathrm{TM}}$ rotary system. The manufacturer reported a decrease of the area in contact with the dentin wall, and that U-shaped grooves had been added at each of the instrument's convex triangular sides to improve flexibility and reduce transportation ${ }^{21}$. Decreasing tapers of the finishing files and increased flexibility of S1 and F1 may have had favorable effects on the performance of the ProTaper Universal $^{\mathrm{TM}}$ rotary system. The ProTaper Universal ${ }^{\mathrm{TM}}$ instruments showed better performance than the conventional ProTaper $^{\mathrm{TM}}$ files evaluated previously, probably because the file tip has been changed from the "modified guiding tip" to the "rounded safe tip". These changes in the instruments may give rise to favorable clinical behavior ${ }^{35}$. On the other hand, Hashem et al. ${ }^{36}$ (2012) observed that the ProTaper Universal $^{\mathrm{TM}}$ system recorded a significantly lesser centering ratio and higher canal transportation than the twisted File, ProFile GT Series X, and Revo-S systems. Similar results were reported and were attributed to the sharp cutting edges and the multiple tapers along the cutting surface of the files ${ }^{1}$.

The use of CBCT revealed that the ProTaper Universal ${ }^{\mathrm{TM}}$ had the capacity of producing centered preparations while Twisted File ${ }^{\mathrm{TM}}$ and $\mathrm{M}_{\mathrm{two}}$ rotary systems produced canal deviation.

\section{Acknowledgments}

This study was supported by grants from National Council for Scientific and Technological Development (CNPq) - Brazil.

\section{References}

1. Gergi R, Rjeily JA, Sader J, NaamanA. Comparison of canal transportation and centering ability of Twisted Files, Pathfile-ProTaper system, and stainless steel hand $\mathrm{k}$-files by using computed tomography. J Endod. 2010; 36: 904-7.

2. El Ayouti A, Dima E, Judenhofer MS, Löst C, Pichler BJ. Increased apical enlargement contributes to excessive dentin removal in curved root canals: a stepwise microcomputed tomography study. J Endod. 2011; 37: 1580-4.

3. Câmara AC, Aguiar CM, Figueiredo JAP de. Assessment of the deviation after biomechanical preparation of the coronal, middle, and apical thirds of root canals instrumented with three Hero rotary systems. J Endod. 2007; 33: 1460-3.

4. Aguiar CM, Mendes D de A, Câmara AC, Figueiredo JAP de. Assessment of canal walls after biomechanical preparation of root canals instrumented with ProTaper Universal ${ }^{\mathrm{TM}}$ rotary system. J Appl Oral Sci. 2009; 17: 590-5.

5. Mendes D de A, Aguiar CM, Câmara AC. Comparison of the centering ability of the ProTaper Universal, ProFile and Twisted File Rotary Systems. Braz J Oral Sci. 2011; 10: 282-7.

6. Ünal GÇ, Maden M, SavgatA, Onur Orhan E. Comparative investigation of 2 rotary nickel-titanium instruments: ProTaper Universal versus ProTaper. Oral Surg Oral Med Oral Pathol Oral Radiol Endod. 2009; 107: 886-92.

7. Kim HC, Yum J, Hur B, Cheung GSP. Cyclic fatigue and fracture characteristics of ground and twisted nickel-titanium rotary files. J Endod. 2010; 36: 147-52.

8. Larsen CM, Watanabe I, Glickman GN, He J. Cyclic fatigue analysis of a new generation of nickel titanium rotary instruments. J Endod. 2009; 35 401-3. 
9. $\quad$ Yang G, Yuan G, Yun X, Zhou X, Liu B, Wu H. Effects of Mtwo versus ProTaper Universal, on root canal geometry assessed by micro-computed tomography. J Endod. 2011; 37: 1412-6.

10. Foschi F, Nucci C, Montebugnoli L, Marchionni S, Breschi L, Malagnino VA, Prati C. SEM evaluation of canal wall dentine following use of Mtwo and ProTaper NiTi rotary instruments. Int Endod J. 2004; 37: 832-9.

11. Hin ES, Wu MK, Wesswlink PR, Shemesh H. Effects of self-adjusting file, Mtwo, and ProTaper. J Endod. 2013; 39: 262-4.

12. Bernardes RA, Rocha EA, Duarte MAH, Vivan RR, Moraes IG de, Bramante AS, Azevedo JR de. Root canal area increase promoted by the EndoSequence and ProTaper systems: comparison by computed tomography. J Endod. 2010; 36: 1179-82.

13. Günday M, Sazak H, Garip Y. A Comparative study of three different root canal curvature measurement techniques and measuring the canal access angle in curved canals. J Endod. 2005; 31: 796-8.

14. Sanfelice CM, Costa FB da, Só MVR, Vier-Pelisser F, Bier CAS, Grecca FS. Effects of four instruments on coronal pre-enlargement by using cone beam computed tomography. J Endod. 2010; 36: 858-61.

15. Gambill JM, Alder M, Del Rio CE. Comparison of nickel-titanium and stainless steel hand-file instrumentation using computed tomography. J Endod. 1996; 22: 369-75.

16. Stern S, Patel S, Foschi F, Sherriff M, Mannocci F. Changes in centring and shaping ability using three nickel-titanium instrumentation techniques analysed by micro-computed tomography $(\mu C T)$. Int Endod J. 2012; 45: 514-23.

17. Venkateshbabu N, Emmanuel S, Santosh GK, Kandaswamy D. Comparison of the canal centring ability of K3, Liberator and EZ Fill Safesiders by using spiral computed tomography. Aust Endod J. 2012; 38: 55-9.

18. Sydney GB, Batista A, De Mello LL. The radiographic platform: a new method to evaluate root canal preparation in vitro. J Endod. 1991; 17: 570-2.

19. Pasternak-Júnior B, Sousa-Neto MD, Siva RG. Canal transportation and centring ability of RaCe Rotary instruments. Int Endod J. 2009; 42: 499-506.

20. Flores CB, Machado P, Montagner F, Gomes BPF de A, Dotto GN, Schmitz M da S. A methodology to standardize the evaluation of root canal instrumentation using cone beam computed tomography. Braz J Oral Sci. 2012; 11: 84-7.

21. Özer SY. Comparison of root canal transportation induced by three rotary systems with noncutting tips using computed tomography. Oral Surg Oral Med Oral Pathol Oral Radiol Endod. 2011; 111: 244-50.

22. Michetti J, Maret D, Mallet JP, Diemer F. Validation of cone beam computed tomography as a tool to explore root canal anatomy. J Endod. 2010; 36 : 1187-90.

23. Pasqualini D, Bianchi CC, Paolino DS, Mancini L, Cemenasco A, Cantatore, Castelluci A, Berutti E G. Computed micro-tomographic evaluation of glide path with nickel-titanium rotary PathFile in maxillary first molars curved canals. J Endod. 2012; 38: 389-93.

24. Schäfer $E$, Oitzinger M. Cutting efficiency of five different types of rotary nickel-titanium instruments. J Endod. 2008; 34: 198-200.

25. Machado ME de L, Sapia LAB, Cai S, Martins GHR, Nabeshima CK. Comparison of two rotary systems in root canal preparation regarding disinfection. J Endod. 2010; 36: 1238-40.

26. Schäfer E, Erler M, Dammaschke T. Comparative study on the shaping ability and cleaning efficiency of rotary Mtwo instruments. Part 2. Cleaning effectiveness and shaping ability in severely curved root canals of extracted teeth. Int Endod J. 2006; 39: 203-12.

27. Mounce RE. Making endo fun again: Get twisted. Dent Econ. 2008; 98:23.

28. Duran-Sindreu F, García M, Olivieri JG, Mercadé M, Morelló S, Roig M. Acomparison of apical transportation between FlexMaster and Twisted Files rotary instruments. J Endod. 2012; 38: 993-5.

29. MarzoukAM, Ghoneim AG. Computed tomographic evaluation of canal shape instrumented by different kinematic rotary nickel-titanium systems. J Endod. 2013; 39: 906-9.
30. Siqueira Júnior JF, Alves FRF, Versiani MA, Rôças IN, Almeida BM, Neves MAS, Sousa-Neto MD. Correlative bacteriologic and microcomputed tomographic analysis of mandibular molar mesial canals prepared by self-adjusting file, Reciproc, and Twisted File systems. J Endod. 2013; 39: 1044-50.

31. Aguiar CM, Sobrinho PB, Teles F, Câmara AC, Figueredo JAP. Comparison of the centering ability of the ProTaperTM and ProTaperUniversalTM rotatory systems for preparing curved root canals. Aust Endod J. 2013; 39: 25-30.

32. Hartmann MSM, Barletta FB, Fontanella VRC, Vanni JR. Canal transportation after root canal instrumentation: a comparative study with computed tomography. J Endod. 2007; 33: 962-5.

33. Huang X, Ling J, Gu L. Quantitative evaluation of debris extruded apically by using ProTaper Universal Tulsa rotary system in endodontic retreatment. J Endod. 2007; 33: 1102-10.

34. Versiani MA, Leoni GB, Steier L, De-Deus G, Tassani S, Pécora JD, Sousa-Neto MD. Micro-computed tomography study of oval-shaped canals prepared with the self-adjusting file, Reciproc, WaveOne, and ProTaper Universal systems. J Endod. 2013; 33: 1060-6.

35. Câmara AS, Martins R de C, Viana ACD, Leonardo R de T, Buono VTL, Bahia MG de A. Flexibility and torsional strength of ProTaper and ProTaper Universal rotary instruments assessed by mechanical tests. J Endod. 2009; 35: 113-6.

36. Hashem AAR, Ghoneim AG, Lutfy RA, Foda MY, Omar GAF. Geometric analysis of root canals prepared by four rotary NiTi shaping systems. J Endod. 2012; 38: 996-1000. 